\title{
Betaines of pyridinium benzimidazolate containing polymethylene interannular spacers
}

\author{
Immaculada Dinarès and Neus Mesquida \\ Laboratori de Química Orgànica, Facultat de Farmacia, Universitat de Barcelona, \\ Av. Joan XXIII s/n,08028-Barcelona \\ E-mail: idinares@ub.edu, neusmesquida@ub.edu
}

Dedicated to Professor Joan Bosch on the occasion of his $60^{\text {th }}$ birthday

\begin{abstract}
We report the first synthesis and relevant structural aspects of some simple examples of the betaines 5-7 and their immediate precursors 8-10. Inner salts $\mathbf{5 b}, \mathbf{6 b}$ and $\mathbf{7 b}$ were isolated, whereas compounds 5a, 6a and 7a were transformed to dihydropyridine derivatives. Their liquid-crystal behavior was examined and for benzimidazolyl pyridinium bromide 8a the secondorder hyperpolarizability $(\beta)$ was measured.
\end{abstract}

Keywords: Betaines, pyridinium, benzimidazolate, dihydropyridines, second-order nonlinear optics materials

\section{Introduction}

The betaine pool comprises a vast array of highly dipolar chemical entities with a low molecular weight, and their properties depend on their dipolar nature. This ensemble of compounds offers the possibility of the coexistence of two terminal rings joined through different spacers with opposite characteristics within heteroaromatic systems: a $\pi$-deficient nucleus (cation, an acceptor group) and a $\pi$-excessive nucleus (anion, donor group). ${ }^{1,2}$

The study of azolium(pyridinium) azolate inner salts with a variety of spacers 1 together with their protonated counterparts 2 , has been part of our research in the field, dealing with their synthesis, structure, reactivity and applications within heterocyclic advanced materials and supramolecular chemistry. ${ }^{2,3}$ 


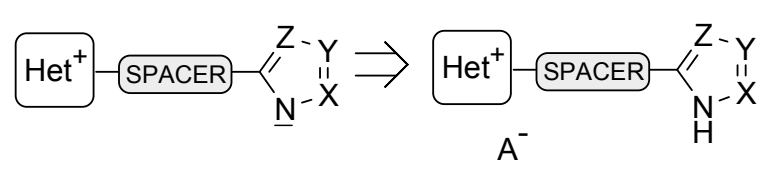

1

2

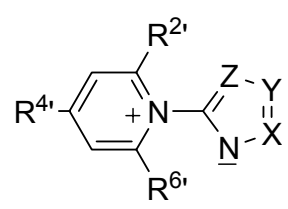

3

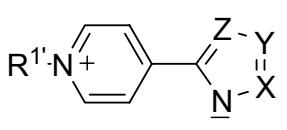

4

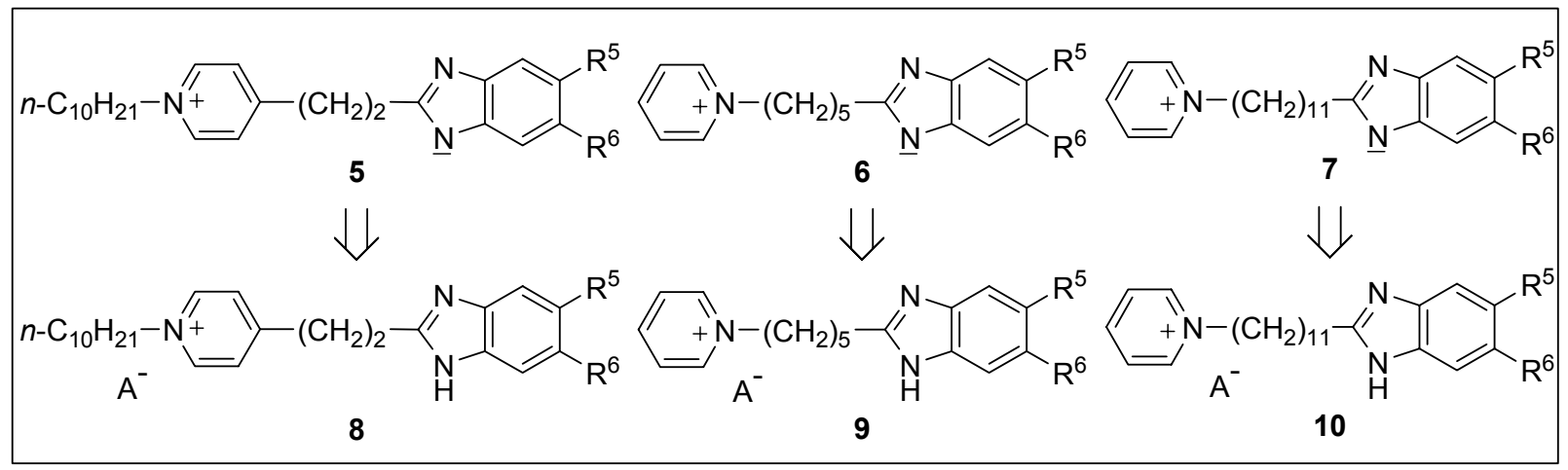

\section{Figure 1}

Initially, we focused our attention on the pyridinium azolate $3^{4 a}$ inner salts with a $\mathrm{C}-\mathrm{N}^{\prime}$ direct bond together with molecules with a betaine character with a $\mathrm{C}-\mathrm{C}^{\prime}$ direct bond $4{ }^{4 \mathrm{~b}}$ subsequently, we extended our study to their heterocyclic betaine homologues with different spacers. ${ }^{2}$

Among these, we have focused our attention on the pyridinium benzimidazolate inner salts with an ethylene linker 5, together with pyridinium benzimidazolate betaines $\mathbf{6}$ and $\mathbf{7}$ with a pentamethylene and undecamethylene spacer, respectively. The dipolar nature of these compounds together with flexible interannular chains provides potential switch behavior, according to whether the medium is acidic or basic. On the other hand, related systems with pyridinium nuclei have demonstrated their application as new materials in liquid crystals ${ }^{5 a, b}$ and in second and quadratic-order nonlinear optics materials (NLO)..$^{5 \mathrm{c}-\mathrm{e}}$

In the present paper, we report the first synthesis and relevant structural aspects of some examples of the betaines 5-7 and their key precursors 8-10.

\section{Results and Discussion}

The syntheses of benzimimidazolylpyridinium salts 8a,b were examined. 1-Decyl-4-[2-(2benzimimidazolyl)ethyl]pyridinium salt 8a was prepared in two steps from pyridylvinyl derivative 12, ${ }^{6}$ and was then reduced with $\mathrm{Pd}-\mathrm{C} 10 \%$ to pyridylethyl derivative 13. Quaternization in neutral conditions was carried out with 1-bromodecane to circumvent the polyalkylation byproducts ${ }^{7}$ affording pyridinium salt $8 \mathbf{a}$ in moderate yield (Scheme 1).

Alternatively, a versatile procedure to access a range of benzimidazolylpyridinium salts with an ethylidene linker was studied and the pyridinium salts 8a,b were obtained from 4pyridylacrylic acid $\mathbf{1 1}$ in three steeps (Scheme 1). Alkylation of pyridine 11 with 1-iododecane 
yields pyridinium salt 14 that was reduced with $\mathrm{Pd}-\mathrm{C} 10 \%$ at 120 psi to propionic acid 15. 1Decyl-4-[2-(benzimidazol-2-yl)ethy]pyridinium salts 8a,b were obtained by condensation of $\mathbf{1 5}$ with appropriate phenylenediamine $\mathbf{1 6 a}, \mathbf{b}$ by classical Phillips benzimidazole synthesis.

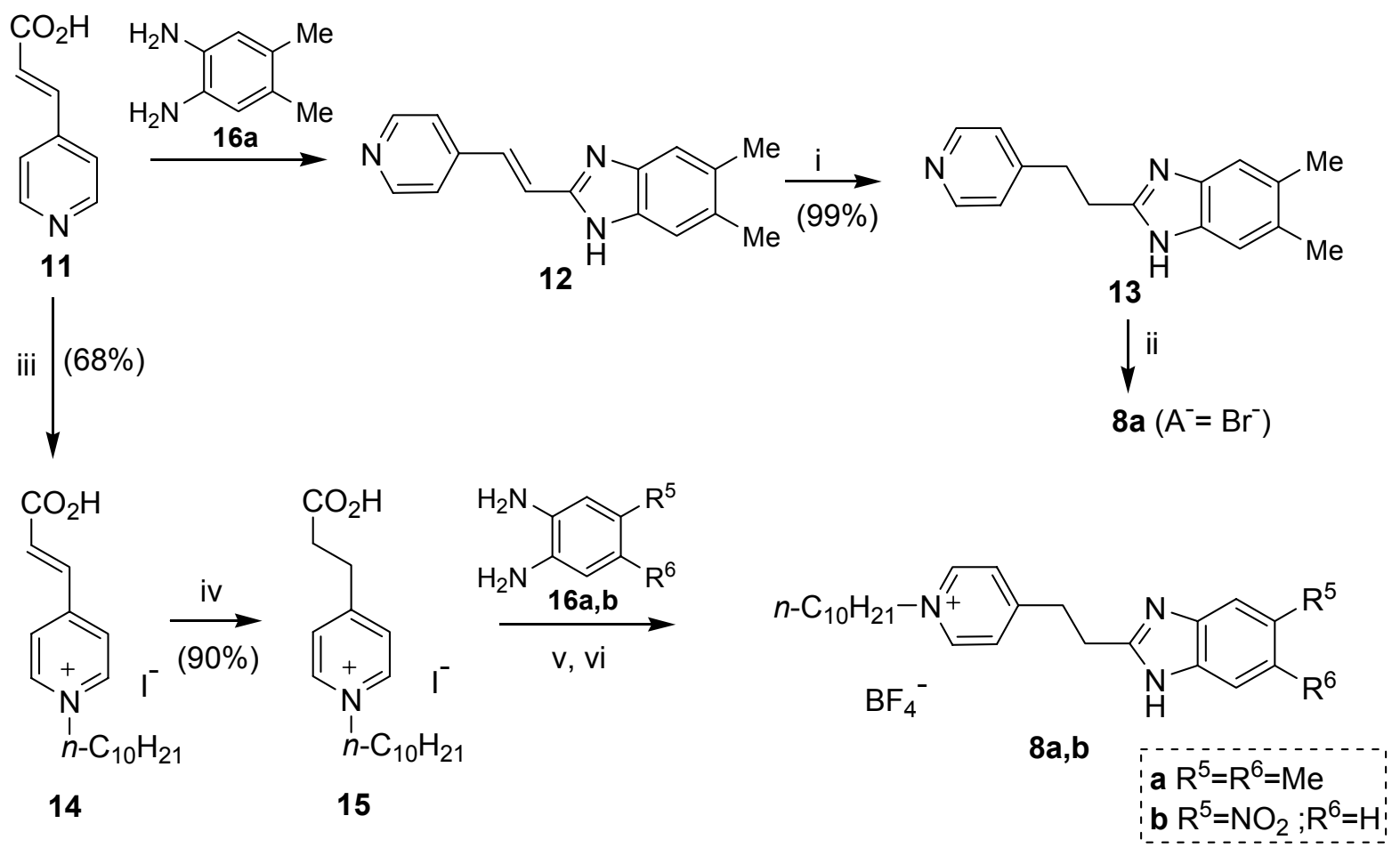

Scheme 1. Reagents and conditions: [i], 10\% Pd-C in dry methanol; [ii], 1-bromodecane in dry acetonitrile, reflux; [iii], 1-iododecane in dry acetonitrile, reflux; [iv],10\% Pd-C in dry methanol, 120 psi; [v], 5N HCl, reflux; [vi] $\mathrm{Na}_{2} \mathrm{CO}_{3}$ to reach $\mathrm{pH} 8 ; 50 \% \mathrm{HBF}_{4}-\mathrm{H}_{2} \mathrm{O}$ to $\mathrm{pH} 6$.

In parallel, benzimidazolylpyridinium salts $\mathbf{9 a , b}$ and $\mathbf{1 0 a , b}$ were prepared in a two-step protocol as shown in Scheme 2. Quaternization of pyridine was carried out with bromoalkyl acid 17-18 to obtain pyridinium derivatives 19-20, which were then efficiently transformed into targeted salts $\mathbf{9 a , b}$ and $\mathbf{1 0 a}, \mathbf{b}$ by reaction with phenylenediamine $\mathbf{1 6 a}, \mathbf{b}$ by Hein's modified benzimidazole synthesis. ${ }^{6}$

Transformation of the aforementioned pyridinium salts $\mathbf{8 b}, \mathbf{9 b}$ and $\mathbf{1 0 b}$ into the corresponding inner salts $\mathbf{5 b}, \mathbf{6 b}$ and $\mathbf{7 b}$ was carried out exploiting our standard protocol, ${ }^{1-4}$ by the use of the anion-exchange Amberlite IRA-401 resin ( $\mathrm{OH}^{-}$form). 


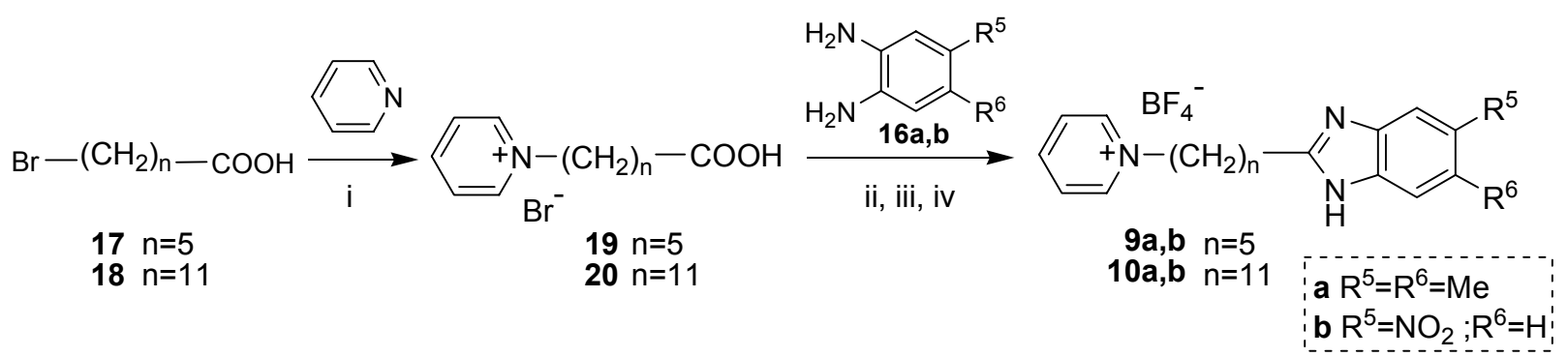

Scheme 2. Reagents and conditions: [i], in dry acetonitrile, reflux; [ii], PPA: method C=160-170 ${ }^{\circ} \mathrm{C}$; method $\mathrm{D}=130-140{ }^{\circ} \mathrm{C}$ (see Experimental Section); [iii], Ice-water; [iv] $\mathrm{Na}_{2} \mathrm{CO}_{3}$ to reach $\mathrm{pH}$ $8 ; 50 \% \mathrm{HBF}_{4}-\mathrm{H}_{2} \mathrm{O}$ to $\mathrm{pH} 6$.

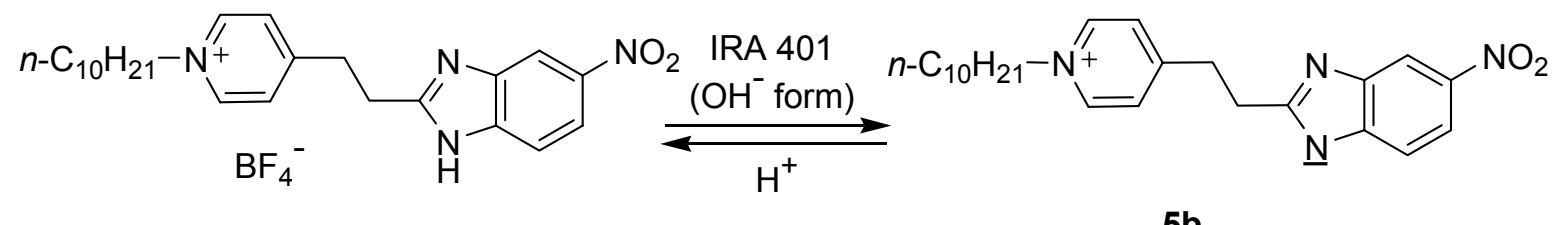

$8 b$

$5 b$

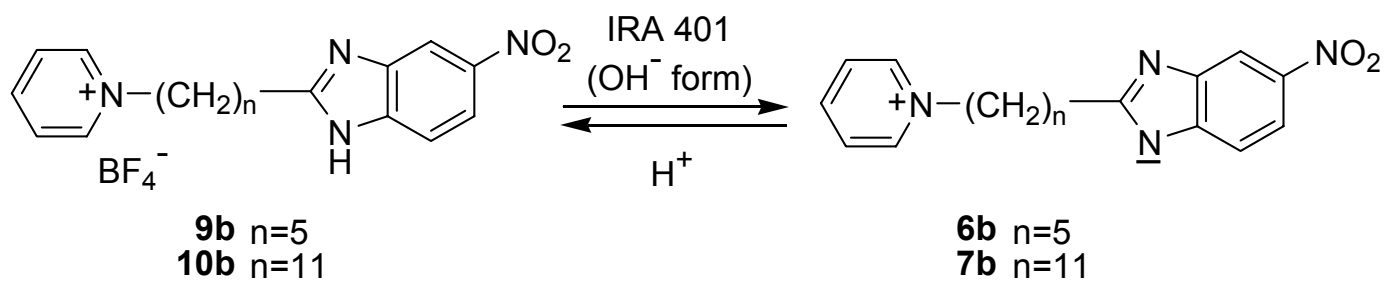

\section{Scheme 3}

Nevertheless, pyridinium benzimidazolate betaines 5a, 6a and 7a were not isolated when the same procedure was used with benzimidazolylpyridinium salts 8a, 9a and 10a (see Schemes 4 and 5). When a solution of pyridinium cations was treated with an anion-exchange resin $\left(\mathrm{OH}^{-}\right.$ form) an intense purple color appeared that turned pale when acid was added. Elimination of solvent under vacuum provided colored solid compounds.

In order to study this transformation, ${ }^{1} \mathrm{H}$ NMR spectra in $\mathrm{DMSO}-\mathrm{d}_{6}$ of $\mathbf{8 a}$ was registered, and then a drop of tetrabutylamonium hydroxide was added to the solution. Chemical shifts of the new spectrum indicated that 1,4-dihydropyridine 21 was formed in basic solution (See Figure 2), and decomposition compounds were formed in 24 hours at room temperature. If TFAA was added to the initial basic solution, pyridinum salt 8a was recovered. An ${ }^{1} \mathrm{H}$ NMR spectrum in DMSO- $_{6}$ of solid compound obtained from fast treatment (less than 1 minute) with Amberlite IRA-401 resin ( $\mathrm{OH}^{-}$form) showed that dihydropyridine 21 was the main component.

Probably, betaine 5a was obtained, but the strong basicity of benzimidazolate anion is enough to form stabilized 1,4-dihydropyridine derivative 21. It is known that in a strong basic 
medium, 4-alkylpyridinium salts react to give an inner salt that is stabilized in 1,4dihydropyridine form. ${ }^{8}$

In addition, experimental deuteration in $\mathrm{CD}_{3} \mathrm{OD}$ confirmed that betaine 5a had been obtained, since $\mathrm{H}$ was immediately exchanged for $\mathrm{D}$ in the methylene bound at position 4 of the pyridine ring. H/D exchange was also observed at positions 2 and 6 of the pyridinium ring.
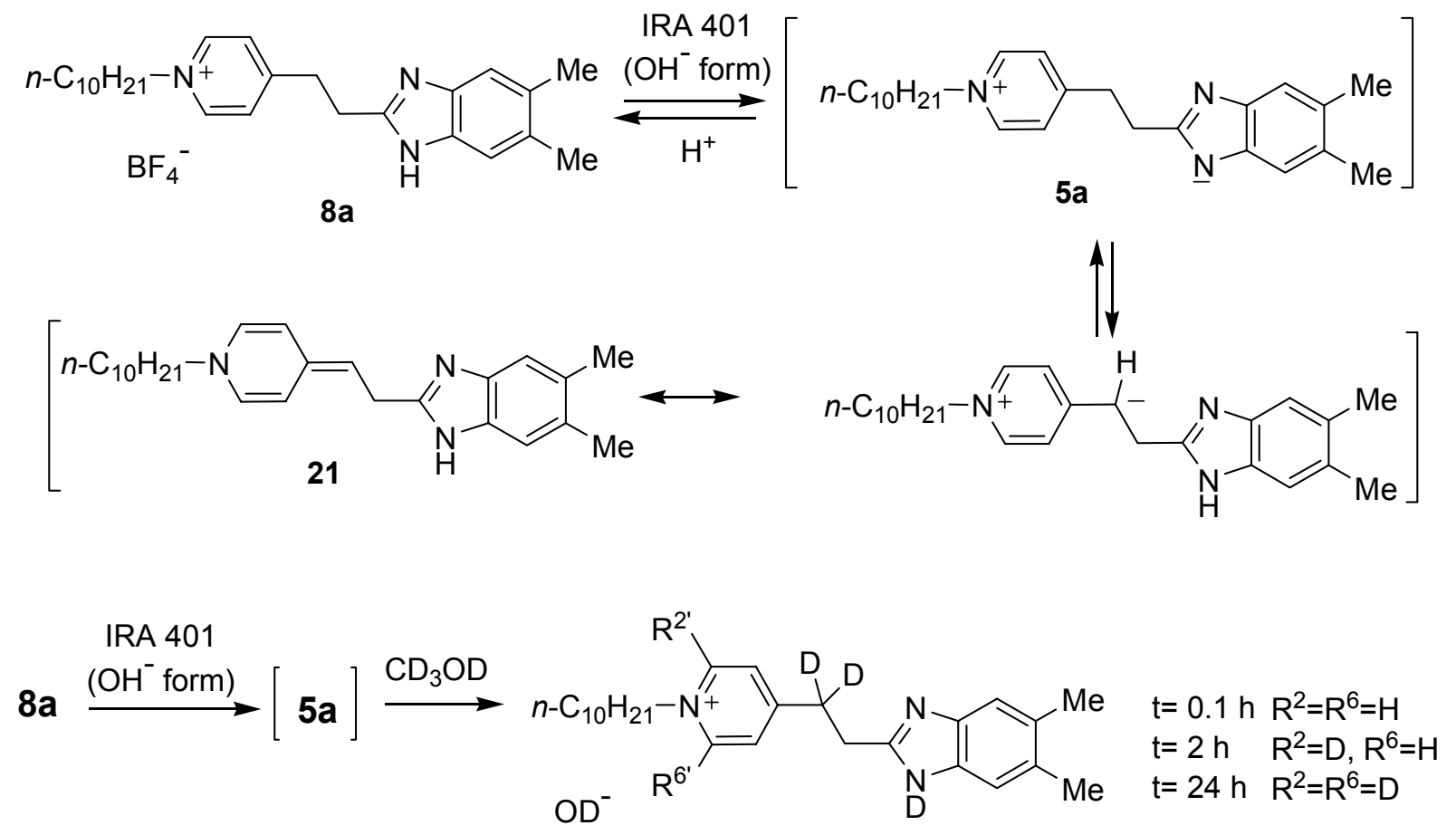

\section{Scheme 4}

Similarly, treatment of both pyridinium salts 9a and 10a with anion-exchange Amberlite IRA-401 resin ( $\mathrm{OH}^{-}$form) afforded colored solid. Formation of decomposition or alteration compounds was observed in their ${ }^{1} \mathrm{H}$ NMR spectra in DMSO- $\mathrm{d}_{6}$. Data obtained in $\mathrm{CD}_{3} \mathrm{OD}$ showed the fast exchange $H / D$ in positions 2 an 6 of pyridinium ring. 

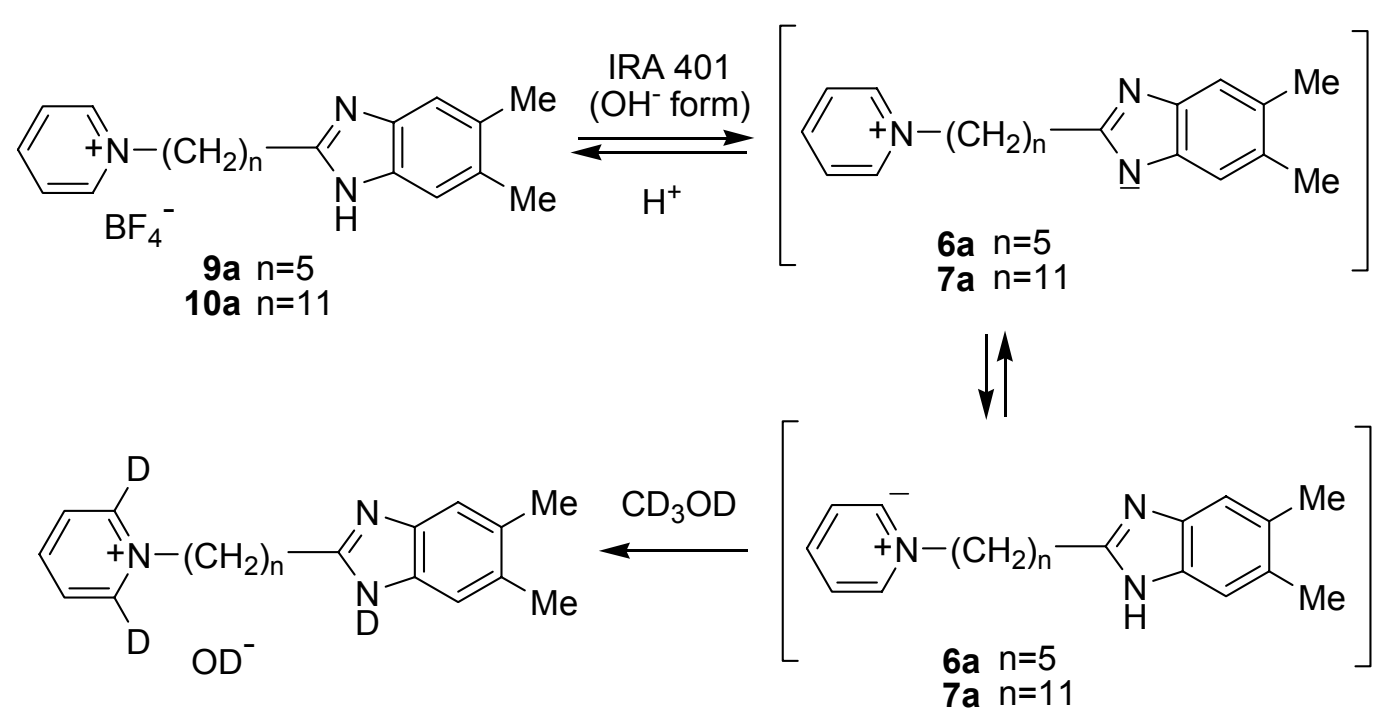

\section{Scheme 5}

Thus, these results proved the high basicity of 5,6-dimethylbenzimidazolate in comparison with 5-nitrobenzimidazolate. Their basic character had been shown when $N$-benzimidazolylethylpyridinium salts were treated with an anion-exchange resin $\left(\mathrm{OH}^{-}\right.$form). ${ }^{9}$ Pyridinium $\beta$-elimination was observed and vinylbenzimidazole was formed through the benzimidazolate intermediate.

Physical data of benzimidazolylpyridinium salts $\mathbf{7 - 1 0 a , b}$ together with pyridinum benzimidazolate inner salts 5-7b are listed in Table 1 (see Experimental Section), and all gave satisfactory elemental analysis.

Table 1. Physical data of compounds 5-7b and 8-10a,b

\begin{tabular}{llllll}
\hline Compd. & Method $^{\mathrm{a}}$ & Time $(\mathrm{h})$ & Yield $(\%)^{\mathrm{b}}$ & $\mathrm{Mp}\left({ }^{\circ} \mathrm{C}\right)$ & Molecular formula $^{\mathrm{c}}$ \\
\hline $\mathbf{5 b}$ & $\mathrm{A}$ & - & 85 & $\mathrm{~d}$ & $\mathrm{e}$ \\
$\mathbf{6 b}$ & $\mathrm{A}$ & - & 96 & $178-179$ & $\mathrm{C}_{17} \mathrm{H}_{18} \mathrm{~N}_{4} \mathrm{O}_{2} \cdot \mathrm{H}_{2} \mathrm{O}$ \\
$\mathbf{7 b}$ & $\mathrm{A}$ & - & 94 & $110-111$ & $\mathrm{C}_{23} \mathrm{H}_{30} \mathrm{~N}_{4} \mathrm{O}_{2} \cdot 0.5 \mathrm{H}_{2} \mathrm{O}$ \\
$\mathbf{8 a}$ & $\mathrm{B}$ & 72 & 66 & $229-230$ & $\mathrm{C}_{26} \mathrm{H}_{38} \mathrm{~N}_{3} \mathrm{BF}_{4} \cdot \mathrm{H}_{2} \mathrm{O}$ \\
$\mathbf{8 b}$ & $\mathrm{B}$ & 125 & 38 & $\mathrm{~d}$ & $\mathrm{e}$ \\
$\mathbf{9 a}$ & $\mathrm{C}$ & 1.5 & 88 & $58-60$ & $\mathrm{C}_{19} \mathrm{H}_{24} \mathrm{~N}_{3} \mathrm{BF}_{4} \cdot 1.5 \mathrm{H}_{2} \mathrm{O}$ \\
$\mathbf{9 b}$ & $\mathrm{D}$ & 1.5 & 81 & $43-44$ & $\mathrm{C}_{17} \mathrm{H}_{19} \mathrm{~N}_{4} \mathrm{O}_{2} \mathrm{BF}_{4} \cdot 0.5 \mathrm{H}_{2} \mathrm{O}$ \\
$\mathbf{1 0 a}$ & $\mathrm{C}$ & 1 & 87 & $60-61$ & $\mathrm{C}_{25} \mathrm{H}_{36} \mathrm{~N}_{3} \mathrm{BF}_{4} \cdot 0.75 \mathrm{H}_{2} \mathrm{O}$ \\
$\mathbf{1 0 b}$ & $\mathrm{D}$ & 1 & 74 & $\mathrm{~d}$ & $\mathrm{e}$ \\
\hline
\end{tabular}

${ }^{\mathrm{a}}$ See Experimental Section. ${ }^{\mathrm{b}}$ Yields were not optimized. ${ }^{\mathrm{c}}$ Satisfactory analytical data $( \pm 0.4 \%$ for $\mathrm{C}, \mathrm{H}, \mathrm{N}) .{ }^{\mathrm{d}}$ Oily compound. ${ }^{\mathrm{e}}$ Not analyzed. 
All new compounds were characterized on the basis of their ${ }^{1} \mathrm{H}$ and ${ }^{13} \mathrm{C}$ NMR data whereas only the ${ }^{1} \mathrm{H}$ NMR parameters were available for the title inner salt $\mathbf{5 b}$, and individual assignments were made using the appropriate NMR experiments (see Tables 2 and 3, and Figure 2).

Table 2. Selected ${ }^{1} \mathrm{H}$ NMR spectroscopic data of (pyridinio)benzimidazolate 5-7b inner salts and (benzimidazolyl)pyridinium tetrafluoroborates 8-10a,b at $200 \mathrm{MHz}$
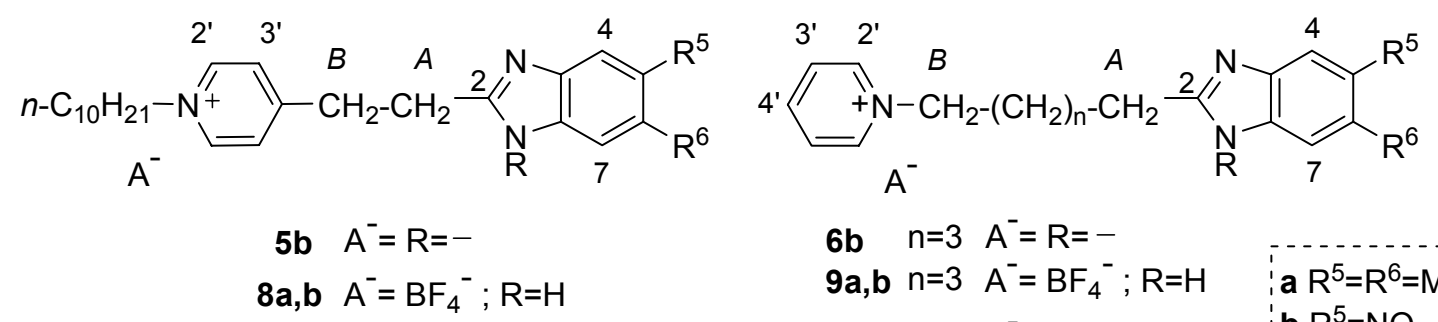

$$
8 \mathbf{a}, \mathbf{b} \quad A^{-}=\mathrm{BF}_{4}^{-} ; \mathrm{R}=\mathrm{H}
$$$$
\text { 6b } \mathrm{n}=3 \quad \mathrm{~A}^{-}=\mathrm{R}=-
$$$$
\text { 9a,b } n=3 \quad A^{-}=B_{4}^{-} ; R=H
$$$$
\text { 7b } n=9 \quad A^{-}=R=-
$$$$
10 a, b \quad n=9 \quad A^{-}=B F_{4}^{-} ; \mathrm{R}=\mathrm{H}
$$

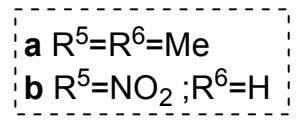

\begin{tabular}{|c|c|c|c|c|c|c|c|c|c|}
\hline Compd. & Solvent & H-2',6' & H-3',5' & H-4' & $\mathrm{H}-4,7$ & $\mathrm{H}-A$ & $\mathrm{H}-B$ & & \\
\hline $8 \mathbf{a}$ & DMSO- $d_{6}$ & 8.93 & 8.03 & - & 7.21 & 3.41 & 3.24 & & \\
\hline $8 \mathbf{a}$ & $\mathrm{CD}_{3} \mathrm{OD}$ & 8.88 & 7.99 & - & 7.32 & 3.57 & 3.42 & & \\
\hline $9 a$ & DMSO- $d_{6}$ & 9.06 & 8.13 & 8.57 & 7.20 & 4.59 & 2.76 & & \\
\hline $9 a$ & $\mathrm{CD}_{3} \mathrm{CN}$ & 8.64 & 7.95 & 8.44 & 7.25 & 4.48 & 2.81 & & \\
\hline $10 a$ & DMSO- $d_{6}$ & 9.05 & 8.58 & 8.14 & 7.19 & 4.56 & 2.72 & & \\
\hline Compd. & Solvent & H-2',6' & $\mathrm{H}-3^{\prime}, 5^{\prime}$ & H-4, & $\mathrm{H}-4$ & H-6 & $\mathrm{H}-7$ & $\mathrm{H}-A$ & $\mathrm{H}-B$ \\
\hline $5 b$ & DMSO- $d_{6}$ & 8.87 & 8.03 & - & 8.12 & 7.70 & 7.24 & $3.33^{b}$ & $3.33^{b}$ \\
\hline $8 b$ & DMSO- $d_{6}$ & 8.95 & 8.09 & - & 8.37 & 8.08 & 7.66 & 3.39 & 3.48 \\
\hline$\Delta \delta^{\mathrm{a}}$ & & -0.08 & -0.06 & & -0.25 & -0.39 & -0.42 & -0.06 & -0.15 \\
\hline $6 b$ & DMSO- $d_{6}$ & 9.06 & 8.08 & 8.54 & 8.09 & 7.66 & 7.18 & 2.72 & 4.58 \\
\hline $9 b$ & DMSO- $d_{6}$ & 9.07 & 8.14 & 8.58 & 8.37 & 8.07 & 7.64 & 2.89 & 4.59 \\
\hline$\Delta \delta^{\mathrm{a}}$ & & -0.01 & -0.06 & -0.04 & -0.28 & -0.41 & -0.46 & -0.17 & -0.01 \\
\hline $6 b$ & $\mathrm{CD}_{3} \mathrm{CN}$ & 8.64 & 7.83 & 8.36 & 8.23 & 7.80 & 7.29 & 2.84 & 4.50 \\
\hline $9 b$ & $\mathrm{CD}_{3} \mathrm{CN}$ & 8.68 & 7.99 & 8.46 & 8.41 & 8.09 & 7.59 & 2.91 & 4.51 \\
\hline$\Delta \delta^{\mathrm{a}}$ & & -0.04 & -0.16 & -0.10 & -0.18 & -0.29 & -0.30 & -0.07 & -0.01 \\
\hline $7 b$ & DMSO- $d_{6}$ & 9.07 & 8.58 & 8.14 & 8.07 & 7.66 & 7.17 & 2.68 & 4.57 \\
\hline $10 b$ & DMSO- $d_{6}$ & 9.08 & 8.59 & 8.14 & 8.36 & 8.05 & 7.60 & 2.83 & 4.56 \\
\hline$\Delta \delta^{\mathrm{a}}$ & & -0.01 & -0.01 & 0.00 & -0.29 & -0.39 & -0.43 & -0.15 & +0.01 \\
\hline
\end{tabular}

${ }^{\mathrm{a}} \Delta \delta$ : observed chemical shift difference between compound pair. ${ }^{\mathrm{b}} \mathrm{Broad}$ band. 
Table 3. Selected ${ }^{13} \mathrm{C}$ NMR spectroscopic data of (pyridinio)benzimidazolate 6-7b inner salts and (benzimidazolyl)pyridinium tetrafluoroborates 8-10a,b in DMSO- $d_{6}$ at $50.3 \mathrm{MHz}$

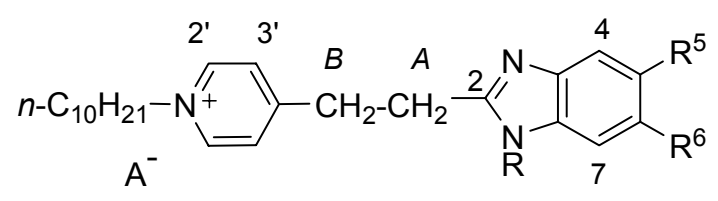

8a,b $\quad A^{-}=B F_{4}^{-} ; \mathrm{R}=\mathrm{H}$

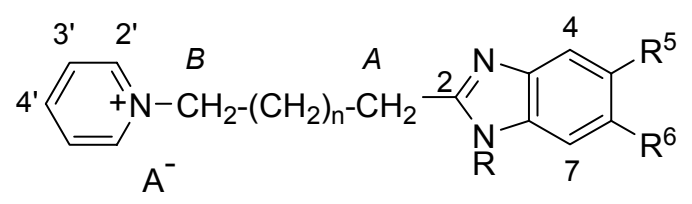

6b $n=3 \quad A^{-}=R=-$

9a,b $n=3 \quad A^{-}=B_{4}^{-} ; R=H$

7b $\quad n=9 \quad A^{-}=R=-$ a $\mathrm{R}^{5}=\mathrm{R}^{6}=\mathrm{Me}$ b $\mathrm{R}^{5}=\mathrm{NO}_{2} ; \mathrm{R}^{6}=\mathrm{H}$

\begin{tabular}{|c|c|c|c|c|c|c|c|c|c|}
\hline Compd. & C-2', $6^{\prime}$ & C-3', $5^{\prime}$ & C-2 & C- 4,7 & C-5,6 & $\mathrm{C}-A$ & C- $B$ & & \\
\hline $8 a$ & 144.2 & 127.9 & 152.2 & a & 129.7 & 28.0 & 32.7 & & \\
\hline 9a & 144.9 & 128.3 & 154.0 & 114.8 & 129.5 & 30.6 & 60.8 & & \\
\hline $9 a^{b}$ & 145.6 & 129.3 & 155.4 & 115.4 & 132.1 & 31.7 & 62.7 & & \\
\hline $10 \mathrm{a}$ & 144.9 & 145.7 & 154.4 & 114.7 & 129.5 & 31.0 & 61.0 & & \\
\hline Compd. & C-2', $6^{\prime}$ & $\mathrm{C}-3^{\prime}, 5^{\prime}$ & $\mathrm{C}-2$ & C-4 & C-7 & C-5 & C-6 & C- $A$ & C- $B$ \\
\hline $8 \mathrm{~b}$ & 144.2 & 128.0 & 158.5 & $\mathrm{a}$ & $\mathrm{a}$ & 142.5 & a & 31.5 & 32.2 \\
\hline $6^{c} b^{c}$ & 145.0 & 128.2 & 171.4 & 111.2 & 113.7 & 146.3 & 113.3 & 31.9 & 60.8 \\
\hline 9b & 145.0 & 128.3 & 160.3 & $113.0^{\mathrm{d}}$ & $113.0^{\mathrm{d}}$ & 142.4 & 117.5 & 30.6 & 60.8 \\
\hline$\Delta \delta^{\mathrm{e}}$ & +0.0 & -0.01 & +11.1 & -1.8 & +0.7 & +3.9 & -4.2 & +1.3 & 0.0 \\
\hline $7 \mathrm{~b}$ & 145.0 & 145.7 & 171.7 & 111.2 & 113.6 & 146.3 & 113.4 & 32.4 & 61.0 \\
\hline $10 \mathrm{~b}$ & 145.0 & 145.7 & 161.4 & 111.7 & 114.1 & 143.7 & 117.2 & 31.0 & 61.0 \\
\hline$\Delta \delta^{\mathrm{e}}$ & 0.0 & 0.0 & $\begin{array}{r}+10.3 \\
\end{array}$ & -0.5 & -0.5 & +2.6 & -3.8 & +1.4 & 0.0 \\
\hline
\end{tabular}

${ }^{\mathrm{a}}$ Not observed. ${ }^{\mathrm{b}}$ In $\mathrm{CD}_{3} \mathrm{OD} .{ }^{\mathrm{c}}$ Assigned by HETCOR experiment. ${ }^{\mathrm{d}}$ Broad signal due to prototropic annular tautomerism. ${ }^{\mathrm{e}} \Delta \delta$ : observed chemical shift difference between compounds pairs $\mathbf{6 b}$ and $9 b$ or $7 b$ and $10 b$.

Thus, the chemical shifts of the $\mathrm{CH}$ protons in the benzimidazole ring in $\mathbf{5 - 7 b}$ moved to lower frequencies, especially H-7 and H-6 (see $\Delta \delta \mathrm{H}-4, \mathrm{H}-6$ and H-7 in Table 2), indicating the change of electron density on the $\pi$-excessive nucleus and the anionic nature of the title compounds, in agreement with data reported for anionic species within benzimidazole systems. ${ }^{1}$ Furthermore, a shielding effect was observed for the methyl protons close to the benzimidazole ring. With regard to the $\pi$-deficient moiety of all compounds, the $\delta \mathrm{H}$ values correspond to quaternary pyridinium structures.

On the other hand, in dihydropyridine derivative 21 signals corresponding to the pyridine ring were found upfield with respect to their precursor 8a together with $\mathrm{CH}_{2}-\mathrm{N}$ (see Figure 2). Moreover, the chemical shifts, multiplicity and integration changed in the ethylidene linker, according to the dihydropyridine structure. 
${ }^{1} \mathbf{H}$ NMR (200 MHz, DMSO-d 6 )
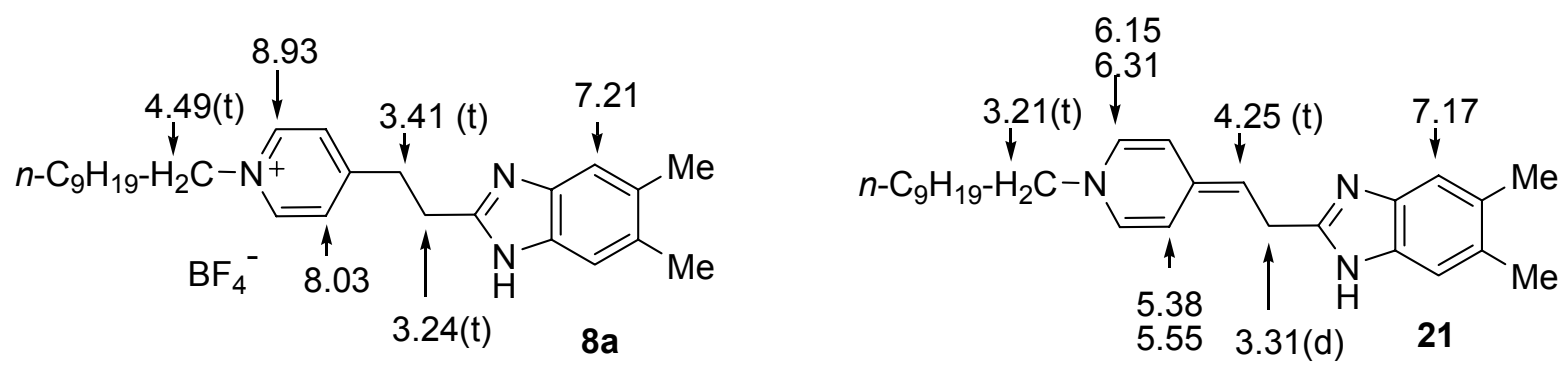

${ }^{13}$ C NMR (50.3 MHz, DMSO-d $)$
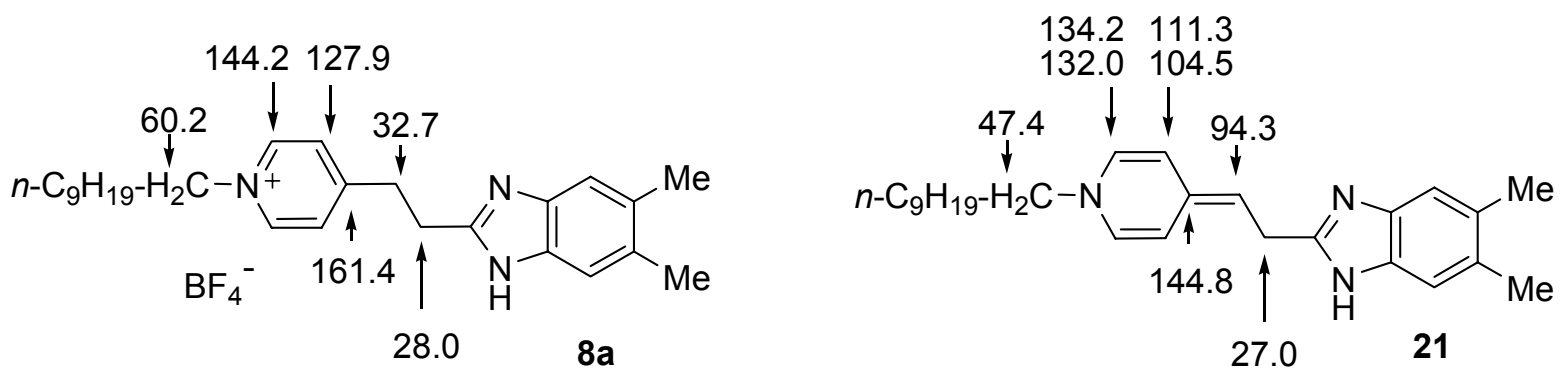

Figure 2. Selected chemical shift data of pyridinium salt 8a and dihydropyridine derivative 21.

As mentioned, the structural characteristics of the compounds reported made them attractive from the advanced materials point of view. ${ }^{2 \mathrm{c}}$ Some of these structures have an elongated geometry similar to ionic liquid crystals reported in the literature. ${ }^{5 a, 10}$ Likewise, the push-pull systems of the betaines and their immediate precursors are closely related to structures successfully studied in nonlinear optics which show high second order parameters ( $\beta$ and/or $\mathrm{X}^{(2)}$ ). Their application in second-order nonlinear optic materials (NLO) has confirmed the value of these dipolar molecular structures and they manifest extremely large first hyperpolarisability in both theoretical $^{5 \mathrm{a}}$ studies and experimental measurements. ${ }^{5 \mathrm{e}}$

Pyridinium benzimidazolate inner salts 6-7b, and benzimidazolylpyridinium salts 8-10a,b were selected for a study of the mesogenic behavior. Surprisingly, none of them showed a clear liquid-crystal behavior. ${ }^{1 \text { a }}$ However, in order to study their properties in NLO, the second-order hyperpolarizability $(\beta)$ of compound 8 a revealed a value between 457 and $1441 \cdot 10^{-30}$ esu in chloroform, ${ }^{11 \mathrm{~b}}$ depending on the concentration (Figure 3$) .{ }^{11}$ The significance of self-association of these compounds were shown again ${ }^{2}$ and high dilution is necessary to study their properties.

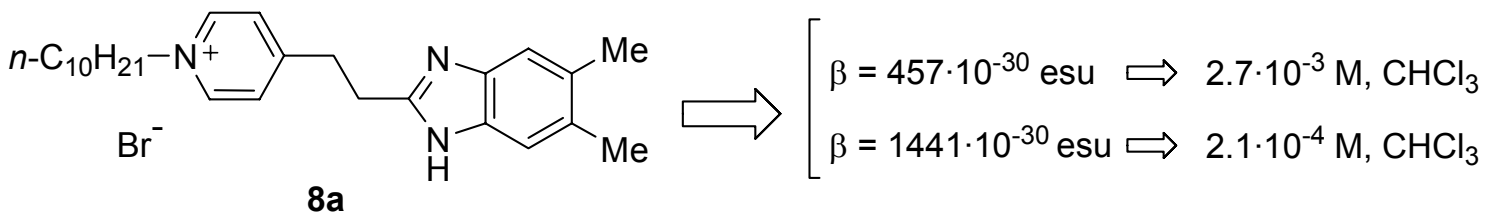

Figure 3. Observed second-order hyperpolarizability $(\beta)$ of compound 8a. 
In summary, new benzimidazolylpyridinium salts 8-10a,b were efficiently prepared and their transformation in basic media were studied. Inner salts 5-7b were isolated, whereas 5-7a evolved to dihydropyridine derivatives. Furthermore, the second-order hyperpolarizability ( $\beta$ ) of compound 8a was measured, and promising values were obtained. The dipolar nature of these compounds together with a flexible interannular chain provides potential switch behavior, according to the acidic or basic media.

\section{Experimental Section}

General Procedures. Melting point: CTP-MP 300 hot-plate apparatus with ASTM 2C thermometer. IR ( $\mathrm{NaCl}$ or $\mathrm{KBr}$ disks): Nicolet $205 \mathrm{FT}$ spectrophotometer. ${ }^{1} \mathrm{H}$ NMR: Varian Gemini 200 and Varian VXR 500 spectrometers $(200 \mathrm{MHz}$ and $500 \mathrm{MHz})$ at $298{ }^{\circ} \mathrm{K} .{ }^{13} \mathrm{C} \mathrm{NMR}$ : Varian Gemini $200(50.3 \mathrm{MHz})$ at $298^{\circ} \mathrm{K}$. HMQC and HMBC experiments: Varian VXR 500 spectrometer $(500 \mathrm{MHz})$. NMR spectra were determined in dimethylsulfoxide- $d_{6}$, methanol- $d_{4}$ or acetonitrile- $d_{3}$, and chemical shifts are expressed in parts per million $(\delta)$ relative to the central peak of dimethylsulfoxide- $d_{6}$, methanol- $d_{4}$ or acetonitrile- $d_{3}$. TLC was performed on Merck precoated $60 \mathrm{~F}_{254}$ silica gel plates in the solvent system methanol-ammonium chloride 2Mnitrometane (6:3:1) as developing solvent; and the spots were located with UV light and developed with a $10 \%$ aqueous solution of potassium iodide or $3 \%$ aqueous solution of hexachloroplatinic acid. Chromatography: neutral aluminum oxide 90 activity II-III (Merck). A standard protocol was applied for counteranion exchange using a strongly basic anion exchange resin (hydroxide form). ${ }^{4}$ When a rotary evaporator was used, the bath temperature was $25{ }^{\circ} \mathrm{C}$. In general, the compounds were dried overnight at $25^{\circ} \mathrm{C}$ in a vacuum oven. Microanalyses were performed on a Carlo Erba 1106 analyzer.

Materials. 1-Bromodecane, 1-iododecane, 6-Bromohexanoic acid 17, 12-bromododecanoic acid 18, 4,5-dimethyl-1,2-phenylenediamine $\mathbf{1 6 a}$ and 4-nitro-1,2-phenylenediamine $\mathbf{1 6 b}$ are commercially available. (E)-3-(4-pyridil)acrylic acid $\mathbf{1 1}^{12}$ and (E)-2-[2-(4pyridil)vinyl]benzimidazole $\mathbf{1 2}^{6}$ were prepared as described in the literature. $N-(5-$ Carboxypentyl)pyridinium bromide $19^{13}$ is also described in the literature.

\section{Method A. General procedure for the preparation of betaines (5-7b) (Table 1) \\ A solution of pyridinium salts $\mathbf{8 b}, \mathbf{9 b}$ or $\mathbf{1 0 b}(c a .200 \mathrm{mg})$ in $96 \%$ ethanol $(50 \mathrm{~mL})$ was passed through a column packed with a strongly basic anion exchange resin (Amberlite IRA 401, hydroxide form). The neutral eluates were evaporated to dryness and then the residue was triturated with diethylether $(20 \mathrm{~mL})$ to give the corresponding betaines $\mathbf{5 b}, \mathbf{6 b}$ or $\mathbf{7 b}$. \\ Method B. General procedure for preparation of 1-decyl-4-[2-(5,6-dimethyl-1H- benzimidazol-2-ylethyl]pyridinium bromide (8a) and 1-decyl-4-[2-(5-nitro-1H- benzimidazol-2-ylethyl]pyridinium tetrafluoroborate $(8 \mathrm{~b})$ (Table 1).}


A stirred suspension of 1-decyl-4-(2-carboxyethyl)pyridinium iodide 15 (1 mmol) and 4,5dimethyl-1,2-phenylenediamine $\mathbf{1 6 a}(1 \mathrm{mmol})$ or 4-nitro-1,2-phenylenediamine $\mathbf{1 6 b}$ (1 mmol) in $5 \mathrm{~N} \mathrm{HCl}(3 \mathrm{~mL})$ was heated in a bath at $135^{\circ} \mathrm{C}$ for the time given in Table 1 . The cooled mixture was poured into ice-water $(25 \mathrm{~mL})$ and the resulting solution was treated with solid $\mathrm{Na}_{2} \mathrm{CO}_{3}$ to reach $\mathrm{pH}$ 8. This solution was then acidified with $50 \% \mathrm{HBF}_{4} / \mathrm{H}_{2} \mathrm{O}$ to reach $\mathrm{pH} 6$ and was extracted with $\mathrm{CH}_{2} \mathrm{Cl}_{2}$. The organic layer was dried, filtered and the solvent evaporated to afford tetrafluoroborates $\mathbf{8 a}$ and $\mathbf{8 b}$, respectively.

Method C. General procedure for the preparation of $N$-[5-(5,6-dimethyl-1H-benzimidazol2-ylpentyl]pyridinium tetrafluoroborate (9a) and $N$-[11-(5,6-dimethyl-1H-benzimidazol-2yl)undecyl]pyridinium tetrafluoroborate (10a) (Table 1)

In a dry, $\mathrm{N}_{2}$-filled three-necked flask fitted with a stirrer, 4,5-dimethyl-1,2-phenylenediamine 16a $(1 \mathrm{mmol})$ and $N$-(5-carboxypentyl)pyridinium bromide 19 or $N$-(11carboxyundecyl)pyridinium bromide 20 (1 mmol) were suspended in polyphosphoric acid (4 $\mathrm{g} / \mathrm{mmol}$ ) and this suspension was heated in a bath at $160-170{ }^{\circ} \mathrm{C}$ for the time given in Table 1 . The cooled mixture was poured into ice-water $(50 \mathrm{~mL})$ and the resulting solution was treated with solid $\mathrm{Na}_{2} \mathrm{CO}_{3}$ to reach $\mathrm{pH}$. This solution was then acidified with $50 \% \mathrm{HBF}_{4} / \mathrm{H}_{2} \mathrm{O}$ to reach pH 6 and was extracted with $\mathrm{CH}_{2} \mathrm{Cl}_{2}$. The organic layer was dried, filtered and the solvent evaporated to afford tetrafluoroborates 9a and 10a, respectively.

Method D. General procedure for the preparation of $N$-[5-(5-nitro-1H-benzimidazol-2ylpentyl]pyridinium tetrafluoroborate $(9 \mathrm{~b})$ and $N$-[11-(5-nitro-1H-benzimidazol-2yl)undecyl]pyridinium tetrafluoroborate (10b) (Table 1)

In a dry, $\mathrm{N}_{2}$-filled three-necked flask fitted with a stirrer, 4-nitro-1,2-phenylenediamine $\mathbf{1 6 b}$ (1 mmol) and $N$-(5-carboxypentyl)pyridinium bromide 19 or $N$-(11-carboxyundecyl)pyridinium bromide 20 ( $1 \mathrm{mmol}$ ) were suspended in polyphosphoric acid $(4 \mathrm{~g} / \mathrm{mmol})$ and this suspension was heated in a bath at $130-140^{\circ} \mathrm{C}$ for the time given in Table 1 . The cooled mixture was poured into ice-water $(50 \mathrm{~mL})$ and the resulting solution was treated with solid $\mathrm{Na}_{2} \mathrm{CO}_{3}$ to reach $\mathrm{pH} 8$. This solution was then acidified with $50 \% \mathrm{HBF}_{4} / \mathrm{H}_{2} \mathrm{O}$ to reach $\mathrm{pH} 6$ and was extracted with $\mathrm{CH}_{2} \mathrm{Cl}_{2}$. The organic layer was dried, filtered and the solvent evaporated to give tetrafluoroborates $\mathbf{9 b}$ and $\mathbf{1 0 b}$, respectively.

2-[2-(4-Pyridil)ethyl]benzimidazole 13. A solution of $(E)$-2-[2-(4-pyridil)vinyl]benzimidazole $12(2.50 \mathrm{~g}, 10 \mathrm{mmol})$ in dry methanol $(150 \mathrm{~mL})$ was hydrogenated at atmospheric pressure in the presence of $0.25 \mathrm{~g}$ of $10 \%$ palladium on carbon. The suspension was filtered from the catalyst through a Celite pad, and concentrated to dryness to give $13(2.48 \mathrm{~g}, 99 \%)$. mp. $165-167{ }^{\circ} \mathrm{C} .{ }^{1} \mathrm{H}$ NMR (DMSO-d $): \delta 8.42(\mathrm{~d}, 2 \mathrm{H}, \mathrm{H}-2,6), 7.24$ (d, 2H, H-3,5), 3.09 (m, 4H), 7.23 (s, 2H, H$\left.4^{\prime}, 7^{\prime}\right), 2.26\left(\mathrm{~s}, 6 \mathrm{H},-\mathrm{CH}_{3}\right)$. Anal. Calcd. for $\mathrm{C}_{16} \mathrm{H}_{17} \mathrm{~N}_{3} \cdot 1 \mathrm{H}_{2} \mathrm{O}: \mathrm{C}, 41.4 ; \mathrm{H}, 7.1 ; \mathrm{N}, 15.6$. Found: C, $71.7 ; \mathrm{H}, 7.2 ; \mathrm{N}, 15.9$.

1-decyl-4-[2-(5,6-dimethyl-1 $H$-benzimidazol-2-ylethyl]pyridinium tetrafluoroborate (8a) from 2-[2-(4-pyridil)ethyl]benzimidazole (13). A stirred solution of 2-[2-(4pyridil)ethyl]benzimidazole $13(0.8 \mathrm{~g}, 3.18 \mathrm{mmol})$ and 1-bromodecane $(2 \mathrm{~mL}, 9.5 \mathrm{mmol})$ in dry acetonitrile $(100 \mathrm{~mL})$ was heated under reflux for 72 hours. After cooling, the solid obtained was 
filtered, washed with diethylether and recrystallized in dry acetonitrile to give bromide $\mathbf{8 a}(0.65$ g, 44\%), mp 102-104 ${ }^{\circ} \mathrm{C}$.

(E)-1-Decyl-4-(2-carboxyvinyl)pyridinium iodide (14). A stirred suspension of (E)-3-(4pyridil)acrylic acid $11(5.0 \mathrm{~g}, 33.55 \mathrm{mmol})$ and 1-iododecane $(21.45 \mathrm{~mL}, 100.65 \mathrm{mmol})$ in dry acetonitrile $(250 \mathrm{~mL})$ was heated under reflux for 10 days. After cooling, the solid obtained was filtered, washed with diethylether and dried to give iodide $14(9.6 \mathrm{~g}, 68 \%), \mathrm{mp} .240-42{ }^{\circ} \mathrm{C} .{ }^{1} \mathrm{H}$

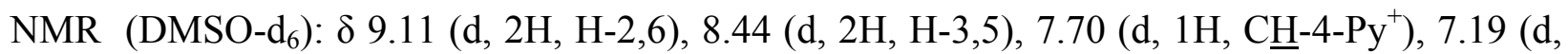
$1 \mathrm{H}, \mathrm{CH}-\mathrm{COOH}), 4.54\left(\mathrm{t}, 2 \mathrm{H}, \mathrm{CH}_{2}-\mathrm{N}\right), 1.88(\mathrm{~m}, 2 \mathrm{H}), 1.22(14 \mathrm{H}), 0.84(\mathrm{t}, 3 \mathrm{H}) .{ }^{13} \mathrm{C}$ NMR (DMSO

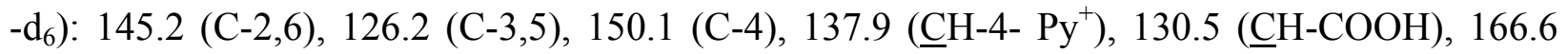
(CO), $60.6(\underline{\mathrm{CH}} 2-\mathrm{N}), 31.5,30.9,29.1,29.0,28.9,28.6,25.6,22.4,14.2\left(\mathrm{C}_{9} \mathrm{H}_{19}\right)$. Anal. Calcd. for $\mathrm{C}_{18} \mathrm{H}_{28} \mathrm{NO}_{2} \mathrm{I} \cdot 0.5 \mathrm{H}_{2} \mathrm{O}: \mathrm{C}, 50.7 ; \mathrm{H}, 6.8 ; \mathrm{N}, 3.3$. Found: C, 50.6; H, 6.6; N, 3.6.

1-Decyl-4-(2-carboxyethyl)pyridinium iodide (15). A solution of (E)-1-decyl-4-(2carboxyvinyl)pyridinium iodide $14(3.5 \mathrm{~g}, 8.5 \mathrm{mmol})$ in dry methanol (400 $\mathrm{mL})$ was hydrogenated at $120 \mathrm{psi}$ of pressure in the presence of $0.35 \mathrm{~g}$ of $10 \%$ palladium on carbon for 24 hours. The suspension was filtered from the catalyst through a Celite pad, and concentrated to dryness to give 13 (3.19 g, 90\%), mp 125-127 ${ }^{\circ} \mathrm{C} .{ }^{1} \mathrm{H}$ NMR (DMSO-d 6 ): $\delta 8.96(\mathrm{~d}, 2 \mathrm{H}, \mathrm{H}-2,6)$, 8.05 (d, 2H, H-3,5), 3.08 (t, 2H, $\underline{\mathrm{C}}_{2}-4-\mathrm{Py}^{+}$), 2.74 (t, 2H, $\left.\underline{\mathrm{C}}_{2}-\mathrm{COOH}\right), 4.50$ (t, 2H, $\left.\underline{\mathrm{H}}_{2}-\mathrm{N}\right), 1.88$ (m, 2H), 1.22 (s.a., 14H), 0.84 (t, 3H). ${ }^{13} \mathrm{C}$ NMR (DMSO - $\left.\mathrm{d}_{6}\right): 173.4$ (CO), 161.7 (C-4), 144.1 $(\mathrm{C}-2,6), 127.9(\mathrm{C}-3,5), 60.2\left(\underline{\mathrm{CH}}_{2}-\mathrm{N}\right)$, , $33.1\left(\underline{\left.\mathrm{CH}_{2}-\mathrm{COOH}\right),} 31.5\left(\underline{\mathrm{CH}}_{2}-\mathrm{Py}^{+}\right), 30.8,30.3,29.1\right.$, 29.0, 28.9, 28.6, 25.6, 22.4, 14.2 (C9H19). Anal. Calcd. for $\mathrm{C}_{18} \mathrm{H}_{30} \mathrm{NO}_{2} \mathrm{I} \cdot 0.5 \mathrm{H}_{2} \mathrm{O}$ : C, 50.6; H, 7.2; N, 3.3. Found: C, 50.6; H, 7.0; N, 3.7.

$\mathrm{N}$-(5-Carboxypentyl)pyridinium bromide (19). ${ }^{13}$ A solution of 6-bromohexanoic acid $(1.0 \mathrm{~g}$, $5.1 \mathrm{mmol})$ and pyridine $(0.41 \mathrm{~mL}, 5.1 \mathrm{mmol})$ in dry acetonitrile was heated at reflux temperature under nitrogen for 5 hours. The reaction solvents were evaporated to dryness, the residue was washed with dry acetone, and the resulting solid was dried to give bromide 19 (2.36r, 86\%), mp. 121-122 ${ }^{\circ} \mathrm{C} .{ }^{1} \mathrm{H}$ NMR (DMSO-d 6 ): $\delta 9.20$ (d, 2H, H-2,6), 8.62 (t, 1H, H-4), 8.17 (d, 2H, H-3,5), 4.65 (t, 2H, $\left.\underline{\mathrm{CH}}_{2}-\mathrm{N}\right), 2.18\left(\mathrm{t}, 2 \mathrm{H}, \mathrm{C}_{2}-\mathrm{COOH}\right), 1.90(\mathrm{~m}, 2 \mathrm{H}), 1.49(\mathrm{~m}, 2 \mathrm{H}), 1.24(\mathrm{~m}, 2 \mathrm{H}) .{ }^{13} \mathrm{C}$ NMR (DMSO-d $\left.)_{6}\right): 174.9$ (CO), 145.3 (C-2,6), $146.0(\mathrm{C}-4), 128.5(\mathrm{C}-3,5), 60.7\left(\underline{\mathrm{CH}}_{2}-\mathrm{N}\right), 33.5$ $\left(\underline{\mathrm{C}} \mathrm{H}_{2}-\mathrm{COOH}\right), 30.6,23.9,25.0$. Anal. Calcd. for $\mathrm{C}_{11} \mathrm{H}_{16} \mathrm{NO}_{2} \mathrm{Br}: \mathrm{C}, 48.2 ; \mathrm{H}, 5.9 ; \mathrm{N}, 5.1$. Found: $\mathrm{C}$, 47.8; H, 5.9; N, 5.0.

$\mathrm{N}$-(11-Carboxyundecyl)pyridinium bromide (20). A solution of 12-bromododecanoic acid (1.5 $\mathrm{g}, 5.4 \mathrm{mmol})$ and pyridine $(0.43 \mathrm{~mL}, 5.4 \mathrm{mmol})$ in dry acetonitrile was heated at reflux temperature under nitrogen for 18 hours. The reaction solvents were evaporated to dryness, the residue was washed with dry acetone, and the resulting solid was dried to give bromide $\mathbf{2 0}$ (2.65 g, 77\%). mp. $150-152{ }^{\circ} \mathrm{C} .{ }^{1} \mathrm{H}$ NMR (DMSO-d 6 ): $\delta 9.08$ (d, 2H, H-2,6), 8.60 (t, 1H, H-4), 8.16 (d, $2 \mathrm{H}, \mathrm{H}-3,5), 4.60\left(\mathrm{t}, 2 \mathrm{H}, \mathrm{CH}_{2}-\mathrm{N}\right), 2.17$ (t, 2H, $\left.\underline{\mathrm{H}}_{2}-\mathrm{COOH}\right), 1.89(\mathrm{~m}, 2 \mathrm{H}), 1.49(\mathrm{~m}, 2 \mathrm{H}), 1.22(\mathrm{~m}$, 14H). ${ }^{13} \mathrm{C}$ NMR (DMSO-d $): 174.8$ (CO), 145.7 (C-2,6), 145.0 (C-4), 128.3 (C-3,5), $60.9\left(\underline{\mathrm{CH}}_{2}-\right.$ N), $33.9\left(\mathrm{CH}_{2}-\mathrm{COOH}\right), 33.9,31.0,29.1,29.0,28.8,28.6,25.6,24.7$. Anal. Calcd. for $\mathrm{C}_{17} \mathrm{H}_{28} \mathrm{NO}_{2} \mathrm{Br}$ : C, 57.0; H, 7.9; N, 3.9. Found: C, 57.0; H, 8.0; N, 3.9. 


\section{Acknowledgements}

This research was supported by the Vicerrectorat de Recerca (2006), Universitat de Barcelona and the Dirección General de Investigación (Ministerio de Educación y Ciencia) project CTQ2006-1182/BQU. Thanks are also due to the AGAUR, 2005SGR00158, (Generalitat de Catalunya)

\section{References and Footnotes}

1. Heterocyclic Betaines, 49. Part 48: Pérez-García, L.; Mesquida, N.; Alemany, M.; Fernández, I.; Vilaseca, M.; Alcalde, E. Eur. J. Org. Chem. 2002, 2691.

2. (a) Alcalde, E. Adv. Heterocycl. Chem. 1994, 60, 197. (b) Alcalde, E.; Dinarès, I.; PérezGarcía, L. Il Farmaco 1999, 297. (c) Alcalde, E.; Dinarès, I.; Mesquida, N.; Pérez-García, L. Targets Heterocycl. Systems 2000, 379.

3. (a) Alcalde,E.; Alemany, M.; Gisbert, M. Tetrahedron 1996, 52, 15171. (b) Alcalde,E.; Mesquida, N.; Fernández, I.; Giralt, E. Rapid Commun. Mass Spectrom. 2000, 14, 1014.

4. (a) Alcalde, E.; Dinarès, I.; Elguero, J.; Fayet, J.-P.; Vertut, M.-C.; Miravitlles, C; Molins, E. J. Org. Chem. 1987, 52, 5009. (b) Alcalde, E.; Dinarès, I.; Frigola, J.; Jaime, C.;Fayet, J.-P.; Vertut, M.-C.; Miravitlles, C; Rius, J. J. Org. Chem. 1991, 56, 4223.

5. (a) Abe, J.; Shirai, Y. J. Am. Chem. Soc. 1996, 118, 4705. (b) Bravo-Grimaldo, E.; NavarroRodríguez, D.; Skoulios, A.; Guillén, D. Liq. Cryst. 1996, 20, 393. (c) Coe, B. J.; Harris, J. A.; Hall, J. J.; Brunschwig, B. S.; Hung, S.-T.; Libaers, W.; Clays, K.; Coles, S. J.; Horton, P. N.; Light, M. E.; Hursthouse, M. B.; Garin, J.; Orduna, J. Chem. Mat. 2006, 18, 5907. (d) Kolev, T.; Stamboliyska, B.; Yancheva, D. Chem. Phys. 2006, 324, 489. (e) Coe, B. J.; Beljonne, D.; Vogel, H.; Garin, J.; Orduna, J. J. Phys. Chem. A 2005, 109, 10052. (f) Nemoto, N.; Abe, J.; Miyata, F.; Y. Shirai, Nagase, Y. J. Mater. Chem. 1998, 8, 1193.

6. Alcalde, E.; Dinarès, I.; Pérez-García, L.; Roca, T. Synthesis 1992, 395.

7. The use of 1-iododecane afforded a mixture of pyridinium, benzimidazolium and pyridiniumbenzimidazolium salts.

8. Abramovitch, R. A. Chem. Heterocycl. Compd. 1974, 14, Part 1, 89 and 351.

9. Alcalde, E.; Pérez-García, L.; Dinarès, I.; Frigola, J. J. Org. Chem. 1991, 56, 6516.

10. (a) Alcalde, E.; Roca, T. Redondo, J.; Ros, B.; Serrano, J. L.; Rozas, I. J. Org. Chem. 1994, 59, 644, and references cited therein. (b) Alcalde, E.; Dinarès, I.; Pons, J.-M.; Roca, T. J. Org. Chem. 1994, 59, 639.

11. (a) In collaboration with Serrano, J. L. and Ros, B. Lab. Química Orgánica, Facultat de Ciencias-ICMA, Univesidad de Zaragoza, Spain. (b) The second-order hyperpolarizability $(\beta)$ was first studied by the EFISH method (electric field induced second harmonic generation).

12. Slater, G.; Soverville, A.W. Tetrahedron 1967, 23, 2823.

13. Dega-Szafran, Z.; Szafran, M. Bull. Pol. Acad. Sci. Chem. 1995, 43, 295. 